\title{
Plasma exchange: are bigger studies necessarily better?
}

\section{Richard Hughes \& Hans-Peter Hartung}

We thank Dr Weinshenker for the opportunity to expand on our commentary on the value of plasma exchange in neurological disorders (Neuroimmunology: Assessing the value of plasma exchange in neurology. Nat. Rev. Neurol. 7, 309-310; 2011) ${ }^{1}$ in which editorial constraints prevented us from referring to all the randomized trials conducted in the field including his and our own. We acknowledge that his crossover trial of plasma exchange in 22 patients with a variety of different acute demyelinating diseases provides the best available evidence for the management of this group of patients (Plasmapheresis: are bigger studies necessarily better? Nat. Rev. Neurol. doi:10.1038/ nrneurol.2011.59-c1). ${ }^{2,3}$ The discovery of anti-aquaporin-4 antibodies in neuromyelitis optica has shown that acute demyelinating diseases have a heterogeneous pathology. It will now be important to obtain further evidence for the efficacy of plasma exchange in different subgroups. We agree that small trials are useful and necessary in rare conditions and that the evidence of two or more trials can be synthesized with careful meta-analysis as commonly done in Cochrane reviews.

Cochrane Neuromuscular Disease Centre, MRC Centre for Neuromuscular Disease, PO Box 114, National Hospital for Neurology and Neurosurgery, Queen Square, London WC1N 3BG, UK (R. Hughes). Department of Neurology, Heinrich-Heine-University Düsseldorf, Moorenstrasse 5, D-40225 Düsseldorf, Germany (H.-P. Hartung).

Correspondence to:

R. Hughes

rhughes11@btinternet.com doi:10.1038/nrneurol.2011.59-c2

\section{Competing interests}

R. Hughes declares associations with the following companies: Baxter, Grifols/Talecris, LFB, Novartis, Octapharma. H.-P. Hartung declares associations with the following companies: Baxter, Bayer Schering, Biogen Idec, CSL Behring, Grifols, Merck Serono, Novartis, Teva. See the article online for ful details of the relationships.

1. Hughes, R. \& Hartung, H. P. Neuroimmunology: Assessing the value of plasma exchange in neurology. Nat. Rev. Neurol. 7, 309-310 (2011).

2. Weinshenker, B. Plasmapheresis: are bigger studies necessarily better? Nat. Rev. Neurol. http://dx.doi.org/10.1038/ nrneurol.2011.59-c1.

3. Weinshenker, B. G. et al. A randomized trial of plasma exchange in acute central nervous system inflammatory demyelinating disease. Ann. Neurol. 46, 878-886 (1999). 